\title{
Evolutionary analysis of vision genes identifies potential drivers of visual differences between giraffe and okapi
}

\author{
Edson Ishengoma ${ }^{\text {Corresp., }}{ }^{1,2}{ }^{\text {， Morris Agaba }}{ }^{1}$ ， Douglas R Cavener ${ }^{3}$ \\ ${ }^{1}$ The School of Life Sciences and Bio-Engineering, Nelson Mandela African Institution of Science and Technology, Arusha, Tanzania \\ 2 Mkwawa University of College of Education, University of Dar-es-Salaam, Iringa, Tanzania \\ 3 Department of Biology and the Huck Institute of Life Sciences, Pennsylvania State University, University Park, Pennsylvania, United States \\ Corresponding Author: Edson Ishengoma \\ Email address: ishengomae@nm-aist.ac.tz
}

Background. The capacity of visually oriented species to perceive and respond to visual signal is integral to their evolutionary success. Giraffe is closely related to okapi, but the two species have broad range of phenotypic differences including their visual capacities. Vision studies rank giraffe's visual acuity higher than all other artiodactyls despite sharing similar vision ecological determinants with many of them. To what extent giraffe unique visual capacity and its difference with okapi is reflected by changes in their vision genes is not understood.

Methods. The recent availability of giraffe and okapi genomes provided opportunity to identify giraffe and okapi vision genes. Multiple strategies were employed to identify thirty-six candidate mammalian vision genes in giraffe and okapi genomes. Quantification of selection pressure was performed by a combination of branch-site tests of positive selection and clade models of selection divergence through comparing giraffe and okapi vision genes and orthologous sequences from other mammals.

Results. Signatures of selection were identified in key genes that could potentially underlie giraffe and okapi visual adaptations. Importantly, some genes that contribute to optical transparency of the eye and those that are critical in light signaling pathway were found to show signatures of adaptive evolution or selection divergence. Comparison between giraffe and other ruminants identifies significant selection divergence in CRYAA and OPN1LW. Significant selection divergence was identified in SAG while positive selection was detected in LUM when okapi is compared with ruminants and other mammals. Sequence analysis of OPN1LW showed that at least one of the sites known to affect spectral sensitivity of the red pigment is uniquely divergent between giraffe and other ruminants.

Discussion. By taking a systemic approach to gene function in vision, the results provide the first molecular clues associated with giraffe and okapi vision adaptations. At least some of the genes that exhibit signature of selection may reflect adaptive response to differences in giraffe and okapi habitat. We hypothesize that requirement for long distance vision associated with predation and communication with conspecifics likely played an important role in the adaptive pressure on giraffe vision genes. 
1 Evolutionary analysis of vision genes identifies potential drivers of visual

2 differences between giraffe and okapi

3 Edson Ishengoma ${ }^{1,2}$, Morris Agaba ${ }^{1}$, Douglas R. Cavener ${ }^{3}$

4

$5 \quad{ }^{1}$ School of Life Sciences and Bioengineering, Nelson Mandela African Institution of

6 Sciences and Technology, Arusha, Tanzania

$7{ }^{2}$ Mkwawa University College of Education, University of Dar es Salaam, Iringa,

8 Tanzania

$9{ }^{3}$ Department of Biology and the Huck Institute of Life Sciences, Pennsylvania State

10 University, USA

11
Corresponding author

Edson Ishengoma

edson.ishengoma@muce.ac.tz

ishengomae@nm-aist.ac.tz 


\section{Abstract}

30 Background. The capacity of visually oriented species to perceive and respond to visual signal is integral to their evolutionary success. Giraffe is closely related to okapi, but the two species have broad range of phenotypic differences including their visual capacities. Vision studies rank giraffe's visual acuity higher than all other artiodactyls despite sharing similar vision ecological determinants with many of them. To what extent giraffe unique visual capacity and its difference with okapi is reflected by changes in their vision genes is not understood.

Methods. The recent availability of giraffe and okapi genomes provided opportunity to identify giraffe and okapi vision genes. Multiple strategies were employed to identify thirty-six candidate mammalian vision genes in giraffe and okapi genomes. Quantification of selection pressure was performed by a combination of branch-site tests of positive selection and clade models of selection divergence through comparing giraffe and okapi vision genes and orthologous sequences from other mammals.

Results. Signatures of selection were identified in key genes that could potentially underlie giraffe and okapi visual adaptations. Importantly, some genes that contribute to optical transparency of the eye and those that are critical in light signaling pathway were found to show signatures of adaptive evolution or selection divergence. Comparison between giraffe and other ruminants identifies significant selection divergence in CRYAA and OPNILW. Significant selection divergence was identified in $S A G$ while positive selection was detected in $L U M$ when okapi is compared with ruminants and other mammals. Sequence analysis of OPN1LW showed that at least one of the sites known to affect spectral sensitivity of the red pigment is uniquely divergent between giraffe and other ruminants.

Discussion. By taking a systemic approach to gene function in vision, the results provide the first molecular clues associated with giraffe and okapi vision adaptations. At least some of the genes that exhibit signature of selection may reflect adaptive 
56 response to differences in giraffe and okapi habitat. We hypothesize that requirement

57 for long distance vision associated with predation and communication with

58

59

60

61

62

63

64

65

66

67

68

69 conspecifics likely played an important role in the adaptive pressure on giraffe vision genes.

\section{Introduction}

Visual cognition is critical to health, survival and evolutionary success of terrestrial vertebrates. Visual perception in mammals is attributable to various aspects such as visual acuity, contrast sensitivity, motion perception, depth perception and color discrimination (Osorio \& Vorobyev, 2005; Kohn, 2007; Heesy \& Hall, 2010). These visual properties are inextricably linked to species evolutionary fitness. They contribute to species competitiveness at food acquisition, predator avoidance, suitable mate recognition, intra-specific communication and locating suitable habitat (Horth, 2007; Tisdale \& Ferna'ndez-Juricic, 2009; Dimitrova \& Merilaita, 2010).

Vision and ecological studies appear to show that considerable differences in visual perception exist between giraffe and other artiodactyls including its close relative, the okapi. Giraffes predominantly rely on visual communication due to their excellent aerial vision (Young \& Isbell, 1991; VanderWaal et al., 2013; Veilleux \& Kirk, 2014). This is partly mediated by their uniquely long legs and neck in comparison to other ruminants (Mitchell et al., 2013). But okapi exhibit poor eyesight and mostly rely on acute sense of smell and hearing to exploit their low light environment (Lindsey, Green \& Bennett, 1999; Greive \& Iwago, 2003). Since giraffes inhabit the open Savannah while okapi are restricted to dense Congo forests, differences in vision between giraffe and okapi could be a function of their ecologies. However, the basis of giraffe's uniquely excellent vision even among other artiodactyls with overlapping ecological niches remains enigmatic. 
83 Although gross morphological and cellular aspects of the eye can contribute to vision 84 differences between species (Pettigrew, 1986; Jeon, Strettoi \& Masland, 1998;

85 Lindsey, Green \& Bennett, 1999; Sivak, Andison \& Pardue, 1999; Cepko, 2014), adaptive variation in vision traits will ultimately be determined by changes at the gene level. Vision in vertebrates is mediated by photoreceptors (rods and cones) which contain visual pigments (opsins) bound to a retinal chromophore (Wald, 1935). Five classes of opsins are expressed in vertebrate photoreceptors: a rod class of pigment RH1 (rhodopsin) enables animals to see in dim light, and four classes of cone pigments which enable perception of distinct color wavelengths. The cone class of pigments include short wavelength sensitive type 1 opsin (SWS1/OPN1SW/L) sensitive in the ultraviolet/violet range of the spectrum at 355-440 nm, SWS type 2 opsin (SWS2) sensitive in the blue range from about 410-490 nm, RH2 opsin (close homolog of RH1) sensitive in the green range from about $480-535 \mathrm{~nm}$, long wavelength opsin (LWS/OPN1LW/L) and middle wavelength-sensitive opsin (MWS/OPN1MW/M) sensitive in the red range from about 490-570nm (Yokoyama, 2002; Bowmaker, 2008).

The cloning of bovine rhodopsin gene by Nathans \& Hogness (1983) inspired efforts to understand variations in molecular genetic mechanisms underlying vision in mammals and vertebrates in general. Comparison of different classes of opsin genes among vertebrates reveals gene loss, gene duplication and nucleotide substitutions to play a fundamental role in the evolution of color vision in vertebrates (Yokoyama \& Radlwimmer, 1998; Yokoyama, 2002; Horth, 2007; Jacobs, 2009). All mammals have apparently lost RH2 cones while SWS2 is retained only in some egg-laying mammals (Hunt et al., 2009). The LWS gene duplication and diversification has resulted into primates possessing both $L W S$ and $M W S$ genes which, respectively, express L-cone pigment maximally sensitive at around $563 \mathrm{~nm}$ and M-cone pigment maximally sensitive at around $535 \mathrm{~nm}$ (Bowmaker 2008). This provides some primates with trichromatic vision due to presence of three spectrally distinct cone pigments expressed by SWS1, MWS and LWS genes (Bowmaker, 2008). But most eutherian mammals remain dichromatic with SWS1 and either MWS or LWS genes (Collin et al., 2009). 
114 With respect to the functional mechanism of opsins, spectral tuning in vertebrates is 115 mainly determined by particular amino acids in the opsin protein structure. Two 116 decades ago, Yokoyama \& Radlwimmer (1998) proposed the "five-sites" rule by 117 demonstrating that sequence changes at sites 180, 197, 277, 285 and 308 were very 118 important in determining variation in LWS spectral sensitivity among mammals. Such 119 sequence variations in visual pigments also occur naturally within species, resulting in 120 spectrally variant subtypes of cone pigments among populations with normal color 121 vision. For example, normal color human subjects show 4-5 nm variations based on 122 whether they possess a Serine or Alanine at position 180 of LWS (Merbs \& Nathans, 123 1992; Kraft, Neitz \& Neitz, 1998). Consequently, there is an interest to determine 124 whether these inter- and intra-species spectral variations in cone pigments confer 125 visual adaptations in species. Several studies on cichlids and a recent work on New 126 World primates suggest that changes in coding sequence of visual pigments may be 127 associated with matching photoreceptor spectral sensitivity to the visual environment 128 of the respective species (Hofmann et al., 2009; Sabbah et al., 2010; Matsumoto et al., 129 2014).

130 While the evolution of opsins and other proteins in the visual phototransduction 131 system has been studied extensively (Larhammar, Nordström \& Larsson, 2009; 132 Invergo et al., 2013), little attention has been given to proteins involved in other 133 processes that impact on whole vision process. Before reaching photoreceptors, light 134 must pass through the ocular media, consisting of sclera, cornea, lens and the vitreous, 135 and these serve to modify and focus light toward the retina. The structure, 136 transparency and light adjustment ability of the ocular media depends on specific 137 constituent proteins (Pierscionek \& Augusteyn, 1993; Winkler et al., 2015). For 138 instance, the sclera and the cornea are packed with collagen fibrils and proteoglycans 139 which provide structural integrity of cornea. An example is lumican (LUM), a low 140 molecular weight leucine-rich proteoglycan with keratan sulfate side chain first 141 identified in the cornea as a regulator for organizing collagen fibers in the cornea 142 (Blochberger et al., 1992; Meek \& Knupp, 2015), but is also present in the sclera and 143 other tissues (Ying et al., 1997). The crucial role of LUM in visual functions is further 144 demonstrated by growing evidence implicating LUM in various ocular defects such as 
145 corneal opacity and high myopia (Chakravarti et al., 1998, 2000, 2003; Austin et al., 146 2002). The eye lens contains high concentrations of proteins known as crystallins 147 which determine lens transparency and refractive power, but $\alpha$-crystallin (CRYAA) is 148 a major type (Nagaraj et al., 2012). Mutations in CRYAA are associated with 149 development of cataracts in humans (Litt et al., 1998; Richter et al., 2008). With the 150 increasing number of whole-genome sequences of many vertebrates, we can now study 151 a broad range of genes enabling functionally integrated traits.

152 For such an evolutionarily important trait as vision, the associated genes will often be 153 subject to purifying selection and therefore are expected to be conserved over 154 evolutionary timescales (Lamb, 2011). However, we recently published giraffe 155 genome and detected signatures of adaptation in few of its vision-associated coding 156 genes (Agaba et al., 2016). These genes included Peripherin-2 (PRPH2) and 157 Cytochrome P450 family 27 (CYP27B1). The PRPH2 encodes a protein integral to 158 rods and cones and mutations in the gene cause various forms of retininis pigmentosa, 159 pattern dystrophies and macular degenerations (Keen \& Inglehearn, 1996). The 160 CYP27B1 codes for an enzyme that hydroxylate Vitamin D and modulate normal 161 calcium and phosphorus homeostasis required for proper development and 162 maintenance of bones. Recently, additional CYP27B1 functions in relation to vision 163 have been proposed which include participating in pathways that counteract 164 inflammation, angiogenesis, oxidative stress and fibrosis. These may in turn confer 165 protection for various retinopathies such as age-related macular degenerations in mice 166 and humans (Parekh et al., 2007; Morrison et al., 2011).

167 In order to elucidate on the evolutionary processes underlying disparity in giraffe and 168 okapi vision, we take advantage of the availability of giraffe and okapi genomes to 169 analyze thirty-six (36) candidate 'visual' genes through comparison with those of closely related species. The objectives are first to identify genes exhibiting signatures of adaptive evolution and/or divergent selection and secondly to relate sequence changes in giraffe and okapi vision proteins to possible changes in visual functions. 


\section{Materials and Methods}

\section{Identification of candidate genes}

176 To obtain candidate vision genes, multiple strategies were utilized to identify proteins 177 with linked roles in vision. The initial step involved downloading all cattle protein 178 sequences from ENSEMBL (Flicek et al., 2012) and screening for proteins annotated 179 with gene ontology (GO) terms "phototransduction" (GO: 0007601), and "visual 180 perception" (GO: 0007602). We used PANTHER (Mi et al., 2013) to first functionally 181 annotate cattle proteins and then screen for those annotated with GO vision terms. The 182 corresponding cattle nucleotide sequences for cattle vision protein were also obtained 183 from ENSEMBL. Since some GO assignments to proteins are not necessarily based on 184 direct experimental evidence but also rely on other evidences such as sequence similarity, we intended to obtain only those genes with proved functions in vision. To achieve this, searches of the literature for proof of gene involvement in vision was performed based upon at least one of the following criteria: (i) the presence of vision disease-associated mutations in human orthologue; (ii) expression in the eye since genes expressed in a given organ at high levels are likely vital in the development and function of that organ and, (iii) interaction with known visual genes and loss of vision in knockout or sporadic mutant mice. Only genes with at least two references linking to a role in vision based on the above criteria were selected. Orthologous mapping of 193 cattle vision proteins to giraffe and okapi genomes returned sequences corresponding to 36 genes. These were the genes that were ultimately used in the analysis (Supplemental File 1).

The lineages, gene sequence alignments and gene trees

Other mammalian taxa were selected on the basis of availability of sequences for the 36 candidate vision genes in the RefSeq dataset of GENBANK (Benson et al., 2013) or ENSEMBL. Sequences with questionable protein coding quality status based upon having incomplete coding sequence or presence of internal stop codons were removed. The sequences for giraffe and okapi candidate vision genes were obtained by performing TBLASTN search using cattle proteins against giraffe and okapi genome sequences that were generated as part the giraffe genome project (Supplemental File 
204 2). Also through TBLASTN searches with cattle vision proteins queries, orthologous 205 nucleotide sequences for all 36 vision genes for the target species were downloaded 206 from NCBI RefSeq mRNA or non-redundant nucleotide database. In case of existence 207 of multiple isoforms for a single gene, the isoform with length similar or closest to 208 giraffe and okapi sequences was selected. This is in recognition of the fact that 209 isoforms with similar or equivalent length are likely evolutionarily conserved with 210 similar function among species (Villanueva-Canas, Laurie \& Alba, 2013). The final 211 list of species, ENSEMBL identity for cattle sequences, RefSeq accession numbers for 212 sequences/isoforms obtained from NCBI and corresponding length for each coding 213 sequence are provided in Supplemental File 3.

214 The coding DNA sequences for each gene were translated to the corresponding protein 215 sequence and sequences with internal termination codons were discarded. The protein 216 sequences were then aligned using MUSCLE release 3.8 (Edgar, 2004). Subsequently, 217 the protein sequence alignments were used as guides for the generation of coding 218 sequence alignments for each gene. This procedure was implemented using RevTrans 219 (Wernersson \& Pedersen, 2003). Phylogenetic trees for each gene were constructed 220 using the HKY85 substitution model of nucleotide evolution and maximum likelihood 221 framework implemented in PhyML Version 3.0 (Guindon \& Gascuel, 2003). 222 Bootstrapping with 100 replicates was performed to be certain of the robustness of the 223 resulting phylogenies.

224 Estimation of the average rates of non-synonymous and synonymous substitutions

225 In order to examine if overall rates of evolution in vision genes contributed to 226 divergence in vision capabilities between giraffe and okapi, the rates of non227 synonymous substitutions per non-synonymous sites (dN) and synonymous 228 substitutions per synonymous sites $(\mathrm{dS})$ were estimated for each branch of the tree 229 using the free ratio model of the codeml program in the PAML package (Yang, 2013). 230 The free-ratio model independently estimates $\mathrm{dN}, \mathrm{dS}$ and $\mathrm{dN} / \mathrm{dS}$ for each branch by 231 assuming that every branch in a tree has a different evolutionary parameter. This is 232 not a robust statistical test for positive selection but the key parameters obtained may 233 provide important information on the relative strengths of selection among species. 
235 Identification of genes and amino acid residues under positive selection

236 To determine adaptive evolution on giraffe and okapi vision genes, signatures of 237 positive selection acting across giraffe and okapi lineages against the background of 238 broad range of mammals was independently assessed for each vision gene. The 239 branch-site test for positive selection was used to identify genes showing signatures of 240 adaptive evolution. The test applies codon models of evolution using normalized 241 nonsynonymous to synonymous substitution rate ratio ( $\omega$ or $\mathrm{dN} / \mathrm{dS})$. By assuming that 242 adaptive evolution is episodic, where few species in a phylogeny and few sites in a 243 protein are affected by selection, it is required to hypothesize a priori a "foreground" 244 branch expected to have evolved under positive selection (Zhang, Nielsen \& Yang, 245 2005). The likelihood scores of branch-site alternative and null selection models 246 based on $\mathrm{dN} / \mathrm{dS}$ as implemented in CODEML of the PAML package were compared 247 using the likelihood ratio test (LRT). Significant case of positive selection was only 248 assumed if LRT yielded $p<0.05$ using the chi-squared distribution at one degree of 249 freedom. For genes that were identified to be under significant positive selection, 250 amino acid residues in the protein sequences that were predicted by Bayes empirical 251 Bayes (BEB) approach (Yang, Wong \& Nielsen, 2005) to belong to the codon class of 252 positive selection on the foreground lineages were identified.

253

254

255

256

257

258

259

260

261

262

263

\section{Clade models analyses of selection divergence}

It has recently been observed that visual adaptations can also be contributed by divergent selective pressure on homologous visual genes of ecologically divergent species (Weadick \& Chang, 2012; Schott et al., 2014). To explore whether giraffe and okapi differences in vision could partially be explained by divergent selection on their vision proteins, the two species were independently compared with other ruminants by applying PAML's Clade Model C (CmC) (Bielawski \& Yang, 2004). The CmC partitions different branches within the phylogeny as "background" and "foreground" as well as existence of three site categories, two of which experience uniform selection across the entire phylogeny (either purifying selection $\left(0<\omega_{0}<1\right)$ or neutral evolution $\left.\left(\omega_{1}=1\right)\right)$ while the third is allowed to vary between background $\left(\omega_{2}\right.$ 
$264>0)$ and foreground $\left(\omega_{3}>0\right)$ branches. The recently developed M2a_rel (Weadick \& 265 Chang, 2012) serves as a useful null model for the CmC. In this analysis, category of 266 genes that contribute to the structural properties of cornea and lens and those that are 267 known to play a direct role in the light signaling function were investigated. Of 36 268 genes, 20 proteins were identified to belong in that category (Supplemental File 4). In 269 the genes which showed significant selection divergence, potential significance of 270 selection divergence was assessed by examining sites which had significant Bayes 271 posterior probability $(>0.75)$ in the divergent site class between target species 272 (giraffe or okapi) and other ruminants. We assessed these sites for possible functional 273 consequences based on literature review of functional studies.

\section{Results}

276

277

278

279

280

281

282

283

\section{Positive selection pressure within the visual genes of giraffe and okapi}

Vision genes, as prescribed by gene ontology (GO) and functional information from literature, were identified in giraffe and okapi that were homologous to other mammals. This screen yielded 36 vision genes which were subjected to a series of analyses to determine selection pressure acting on these genes. Based on $\mathrm{dN}$, dS and $\mathrm{dN} / \mathrm{dS}$ parameters as estimated by the free-ratio model, no significant differences of the three evolutionary parameters were observed between giraffe and okapi. In both species, overall $\mathrm{dN}, \mathrm{dS}$ and $\mathrm{dN} / \mathrm{dS}$ for each of the 36 vision genes were lower than $0.005,0.05$ and 0.1 , respectively, suggesting that vision genes have evolved under strong purifying selection as expected.

The branch-site test of positive selection was performed on all 36 genes and identified lumican gene $(L U M)$ as the only candidate exhibiting positive selection among the 36 vision genes in the okapi lineage (Figure 1A). Aside from PRPH2 and CYP27B1 which had previously been shown to be candidates for adaptive evolution in giraffe (Agaba et al., 2016), no additional candidates of positive selection were identified in the giraffe lineages by the present analysis. Substitution analysis shows that the majority of sites ( $>80 \%)$ are conserved between okapi and closely related 
293 cetartiodactyl mammals (Figure 1B). Positive selection in okapi's LUM is predicted to 294 occur at a single codon site, GCG, at position 36 which encodes Alanine (A). This site 295 exhibit strong posterior probability (0.94). The corresponding codon position in 296 giraffe is AGA while in other species is AGG both of which encode Arginine (R). 297 Besides the strong BEB posterior probability associated with codon position 36, there 298 is also a peculiar observation that R36A substitution seems to have required at least 299 two substitutions in the lineage leading to okapi.

300 To further evaluate the mechanisms of LUM's codon 36 evolution and obtain context 301 of the changes leading to 36A in okapi, ancestral LUM sequences at the interior nodes 302 were reconstructed using a broader vertebrate phylogeny. Apparently, only five 303 unique amino acid replacements at codon 36 were found in the whole vertebrate tree 304 (Figure 1B). Two of these changes occur deep within the phylogeny while three 305 involve terminal nodes and their immediate ancestors. The common ancestor of all 306 vertebrates appears to possess Proline (P, encoded by CCA) at this position. The most 307 ancient nonsynonymous change leads to Glutamine (Q, CAA) in the common ancestor 308 of mammals, followed by another nonsynonymous step leading to R (CGA) in the 309 ancestor of ungulates. For the terminal taxa, convergent replacements R36A and 310 Q36A are respectively observed in okapi and the Malayan colugo (Galeopterus 311 variegatus) (Figure 1C). Closer inspection of okapi and colugo protein sequences did 312 not reveal other convergent changes (Zhang \& Kumar, 1997). But using a branch-site 313 test, a hypothesis of adaptive evolution on convergent site possibly due to similar 314 selective pressure in both lineages was found to be significant $(P<0.001)$.

315

316

317 318

\section{Divergent selection pressure has shaped the evolution of giraffe and okapi} important vision genes

The branch-site model assumption that adaptive evolution is determined by the presence of positive selection in foreground branches ignores the possibility that significant variation in $\omega$-ratios among all branches and sites may also be indicative of adaptive pressure (Schott et al., 2014). For the vision genes studied here, it is possible that specific branch(es) on the tree exhibit sites variation due to selection divergence. Upon examination of selection divergence using clade model $\mathrm{C}$ of Bielawski and Yang 
323 (2004) comparing giraffe or okapi and other ruminants in twenty genes critical to light 324 transmission and light signaling processes, significant results were obtained for three 325 genes while the rest were found to be not significant. Significant genes were $S A G$ 326 (found divergent between okapi and other ruminants), CRYAA and OPN1LW (found 327 divergent between giraffe and other ruminants) (Table 1).

328 In all three significant cases, vast majority of the sites (about 95\%) were under strong 329 purifying selection in both foreground and background lineages to keep their 330 functions, while the proportion of divergent site classes was about 5\%. The 331 proportions of neutrally evolving sites were negligible. Notably, divergently evolving 332 sites were under stronger purifying selection in $S A G$ and $C R Y A A$ in the foreground 333 lineages than in the background lineages (Figure 2A and Figure 2B). Furthermore, 334 several residues in $S A G$ and $C R Y A A$ at some divergently evolving sites are observed to 335 be shared between giraffe and okapi (Figure 2A and Figure 2B).

336 For the divergent site class in $O P N 1 L W$, a remarkable case of rate acceleration was 337 observed in the foreground lineage $(\omega=339.6)$ compared with the background 338 lineages. Because it is theoretically possible for novel functions to be associated with 339 selection divergence in orthologous genes, we next identified sites predicted to have 340 high $(>0.75)$ posterior probability score as determined by PAML's Bayesian 341 computation. According to the five-sites rule, substitutions involving Serine (S), 342 Alanine (A), Tyrosine (Y), Histidine (H), Phenylalanine (F) and Threonine (T) at sites $343180,197,277,285$ and 308 of the L-opsin exert cumulative change in spectral shifts. 344 In particular, the S180A, H197Y, Y277F, T285A and A308S substitutions modulate 345 absorption spectrum by decreasing 7,28, 7, 15 and $16 \mathrm{~nm}$, respectively, from the 346 maximum wavelength in an additive manner (Yokoyama \& Radlwimmer, 1999). The 347 reverse substitutions increase the maximum absorption spectrum by the same 348 measures. Significant posterior probability scores in OPN1LW were found at amino 349 acid site 180 and 233, which correspond with A180S and S233T. These substitutions 350 are unique in giraffe when compared with other ruminants (Figure 2C). Except for the 351 A180S substitution, the other residues in the context of five-sites rule are identical 352 between giraffe and other ruminants. The second giraffe specific substitution (S233T) 
353 also occurs at another spectrally important site within transmembrane domain 5 of the

354 red pigment (Figure 2D), where the A233S substitution has been observed to shift the 355 wavelength by $1 \mathrm{~nm}$ (Winderickx et al., 1992).

356 To gain further insight into the functional significance of giraffe's OPN1LW selection 357 divergence, we examined OPN1LW across broad range of mammals for possible 358 functional convergence associated with the five critical sites. It can be observed that 359 the entire OPNILW gene tree is faithfully concordant with species phylogeny (Figure 360 3). An inspection of codons corresponding to sites 180, 197, 277, 285 and 308 of 361 OPN1LW shows similarities in the allelic combination of giraffe amino acids at the 362 respective sites with pinnipeds, bats and some primates (Table 2). In these taxa, the 363 overrepresented allele at the five sites is S, H, Y, T and A (henceforth denoted here as 364 SHYTA) for sites 180, 197, 277, 285 and 308, respectively. Giraffe's SHYTA allele, 365 although unique to ruminants, is observed in common with some humans, some old366 world primates, walrus and vesper bats.

367 The pattern of allelic combination shows sites 197, 285 and 308 to be invariant in 368 these taxa while site 180 shows some degree of S/A variation between- and within369 species. In particular, humans are known to be polymorphic for the S/A allele at site 370180 of OPN1LW (Winderickx et al., 1992). The SHYTA and AHYTA forms of human 371 OPN1LW have their respective $\lambda_{\max }$ experimentally determined by Merbs \& Nathans 372 (1992) at $557 \mathrm{~nm}$ and $552 \mathrm{~nm}$. If the identity of residues at the five sites is a reliable 373 predictor of spectral tuning (and several experiments suggest it is (Table 2)), then a $3745 \mathrm{~nm}$ variation in the $\lambda_{\max }$ of LWS pigments between giraffe and other ruminants is 375 expected.

377 Discussion

378 The development of distinct attributes between species for a given trait is typically 379 complex involving a large number of genes. The visual system is well known to be 380 comprised of the actions of many genes, some of which exhibit tissue- and/or cell381 type restricted functions (Siegert et al., 2012). In this study, we performed an 
382 evolutionary analysis on several genes participating in wide variety of visual process.

383 The ultimate aim is to determine molecular genetic basis and evolutionary factors 384 underlying giraffe excellent vision and its apparent disparity with that of okapi.

385 We discovered positive selection and selection divergence in genes with predominant 386 roles in corneal, lens and retinal functions in both organisms. This suggests that the 387 focal point of selection on the vision phenotype may not be limited to a single 388 functional unit. Rather, the interplay of different elements in the visual pathway 389 appears to be mirrored by the operation of natural selection on functionally diverse 390 vision genes, possibly to adjust species' vision to the myriad of complexity of their 391 visual environment. This potentially concerted adaptive strategy is likely partly due to 392 the intricate functional matching between ocular and retinal aspects, a phenomenon 393 perhaps well demonstrated in teleost fish and birds' visual systems. For example, in 394 cichlids and birds, the degree by which the lens of particular species filters ultra395 violet (UV) light is reflected by the levels of expression or possession of their UV 396 pigments (Hofmann et al., 2010; Lind et al., 2014). Recent findings also suggest 397 widespread differential capacities in ocular transmittance of UV light among 398 mammals (Douglas \& Jeffery, 2014). The fundamental question is whether a pattern of 399 selection signatures detected in okapi and giraffe vision genes is specifically an 400 adaptive response imposed by their visual environment, or whether it is a pattern 401 specific for other purposes. Our study can only provide insight on the likely role of 402 environment influences on the evolution of vision genes in giraffe and okapi.

403

404 405

406 407 408 409 410 411

Among okapi vision genes, $L U M$ is shown to have undergone positive selection. The irradiance spectrum at the floor of the low-light forest environment in which the okapis are confined is expected to be dominated by shorter wavelengths in the bluegreen, blue and even ultraviolet ranges (Honkavaara et al., 2002; Warrant \& Johnsen, 2013). Recently, Douglas \& Jeffery (2014) shows okapis to possess a higher degree of UV transmission through their ocular media than closely related artiodactyls living in the open environment. Although specific sites required for LUM interaction with collagens are not yet identified (but see Kalamajski \& Oldberg, 2009)), the probable site under positive selection shows signal of convergent adaptation with the nocturnal 
412 Malayan colugo (Figure 1B). Okapi and colugo are evolutionarily diverse organisms 413 but one thing that they have in common is their low light forest habitat and nocturnal 414 lifestyles. In general, nocturnal mammals tend to have eyes adapted to transmit and 415 process UV (Zhao et al., 2009; Douglas \& Jeffery, 2014). It is therefore likely that the 416 convergence of positive selection in $L U M$ in okapi and Malayan colugo may be 417 associated with ocular adaptations related to spectral transmittance and survival in 418 reduced light environment.

419 Another gene found to exhibit signature of selection in okapi is $S A G$. Recently, $S A G$ 420 was found to show strong evidence of convergent evolution in species adapted to dim421 light vision (Shen et al., 2012). Arrestin binds to photoactivated and phosphorylated 422 rhodopsin, a process that desensitizes rhodopsin and regulates the signaling process. 423 The mutation in the gene causes congenital stationery night blindness and other retinal 424 diseases (Kuhn, Hall \& Wilden, 1984; Fuchs et al., 1995; Nakazawa, Wada \& Tamai, 425 1998). It might be that evolutionary changes in LUM (associated with corneal 426 transparency) and $S A G$ (important in rod mediated vision) could confer okapi with 427 concerted adaptive mechanisms associated with requirement for low light vision and 428 exploitation of the deep forest niche.

Besides PRPH2 and CYP27B1 (Agaba et al., 2016), this study further identifies 430 selection divergence in CRYAA and OPN1LW between giraffe and other ruminants. 431 Observed amino acid changes associated with selection divergence in giraffe's CRYAA 432 are shared with okapi and in some cases with other ruminant species (Figure 2B). This may suggest common phylogenetic signal or shared functional variation. In the latter case, we would expect the rate of molecular evolution on $C R Y A A$ to be determined by the extent of selective constraint associated with maintenance of vision among species. Mammals such as the subterranean mole rat exhibit an accelerated rate of CRYAA evolution at nonsynonymous positions when compared with the visually oriented rodents, consistent with the mole rat little need for vision (Hendriks et al., 1987). Since variation in visual qualities are observed among artiodactyls (Veilleux \& 
441 CRYAA may reflect the degree of reliance on $\alpha \mathrm{A}$-crystallin functions in the lens

442 associated with relative visual requirements of giraffe and other ruminants.

443 But a comparison of giraffe's $O P N 1 L W$ with those of other ruminants identifies two 444 unique changes that could provide giraffe with unique color-based tuning (Figure 2D). 445 The first change is the S233T which occurs in TM5 of the receptor (Figure 2D). The 446 location of the change is potentially important for the "chloride effect", a phenomenon 447 observed to be widespread in vertebrate L-cone pigments (Wang, Asenjo \& Oprian, 448 1993; Hirano et al., 2001). In vertebrates, the binding of chloride ion at H197 in both 449 L- and M- cone pigments contributes to the red-shift of the chromophore's absorption 450 in the visual pigments. Whatever shift caused by S233T in the L-cone spectral tuning, 451 it is most likely to be subtle as both Serine and Threonine are hydroxyl-bearing amino 452 acids (Merbs \& Nathans, 1993). Establishing actual impact of S233T in the spectral 453 tuning of the L-cone pigment requires functional studies.

454 The second change is the A180S substitution at one of the five functionally significant 455 sites of the red opsin. This confers giraffe with an SHYTA allele compared with an 456 AHYTA allele observed in okapi and other ruminants in the study. Based on the five457 sites rule, this is expected to provide giraffe with at least $5 \mathrm{~nm}$ spectral-shift toward 458 red when compared with other ruminants (Yokoyama \& Radlwimmer, 1998, 1999). It 459 should be noted, nevertheless, that the two giraffe individuals sequenced in the project 460 are insufficient to conclude that A180S substitution is fixed in the giraffe populations. 461 Hence, the site may as well be polymorphic in giraffes as in humans.

462 If sequence changes observed in giraffe's OPN1LW confer giraffe with adaptive 463 benefits over other ruminants, these advantages can only be speculated upon based on 464 some common environmental challenges with other species with which it shares the 465 SHYTA genotype. This is based on the key assumption that distantly related species 466 facing common or related problems are likely to respond by developing convergent 467 solutions (Stern, 2013). It is, therefore, notable that giraffe share the SHYTA 468 genotype with distantly related mammals such as pinnipeds, bats and some primates 469 (Table 2). This may reflect some functional convergence associated with LWS color 470 discrimination among these species. 
471 Pinnipedia (seals and walruses) are marine mammals whose existence depends upon

472 switching their lives between land and shallow coastal waters. In coastal waters, 473 where seals and walruses spend majority of their time, are dominated by longer 474 wavelength colors such as green and red (Wozniak \& Dera, 2007). Because of their 475 amphibious lifestyle, seals and walruses are presented with the need to adapt to the 476 dominant spectral irradiance when in water and also maintain some color vision when 477 on land (Griebel \& Peichl, 2003). Apparently, pinnipeds, in their course of evolution, 478 have become cone monochromats after losing functional S-cone pigment and retaining 479 only L-cone pigment (Crognale et al., 1998). Presence of five-sites SHYTA genotype 480 in pinniped L-cone pigment could provide optimal ability to contrast rod and cone 481 signals necessary for residual color vision they may possess (Crognale et al., 1998; 482 Griebel \& Peichl, 2003).

483 The importance of red color vision in bats is not clear but some bat species, including 484 fruit-eating bats, possess intact, functionally constrained OPN1LW gene that, on its 485 own, may provide bats with spectral mechanism for increased sensitivity during 486 navigation and foraging (Wang et al., 2004). Alternatively, since bats are nocturnal 487 mammals, their red color sensitivity could depend on the Purkinje shift. The Purkinje 488 effect is the apparent reduction in brightness of red object under dim light conditions 489 as a result of comparison of signal generated by the $\lambda_{\max }$ of rhodopsin and that of the 490 MWS/LWS opsins (Trezona, 1970). Under conditions where bats might benefit from 491 signal inputs of both cone and rod systems, for example under twilight at dusk or 492 dawn (Pavey et al., 2001; Melin et al., 2014), the SHYTA genotype may provide a 493 spectral mechanism to compensate for the Purkinje effect.

494 Anthropoid primates (consisting of New World and Old World monkeys) are usually 495 regarded as visual specialists due to their keen visual acuity and color perception 496 (Kirk \& Kay, 1990; Kawamura, 2016). Indeed, the best example in higher mammals 497 linking sequence variation in $\mathrm{L} / \mathrm{M}$ opsin to visual behavior in an ecological context is 498 observed in primates. In ateline New World primates which exhibit allelic variation at 499 three of the five spectrally important sites in the L-opsin (where SYT, SFT, AFT and 500 AFA at site 180, 277, and 285, respectively, are common variants), possession of SYT 
501 is likely advantageous among primates in identifying ripe fruits in the background of 502 green leaves (Matsumoto et al., 2014).

503 As a general rule, matching of cone pigments spectral characteristics to spectral 504 reflectance of the visual environment (Lythgoe, 1984), should provide clues to 505 ecological factors driving visual genetic adaptations in species. For example, all 506 woolly lemurs (Avahi spp) endemic to Madagascar forests uniformly possess cone 507 pigment allele with $\lambda_{\max }$ precisely tuned to the spectral reflectance of the preferred 508 diet of young leaves (Veilleux et al., 2013). Likewise, diversification in the cone 509 pigment spectral sensitivity in fish species influences detection of prey and 510 communication with conspecifics (Sabbah et al., 2010). But the suite of ecological 511 factors more likely to play an important role in vision adaptations is shared among 512 ruminants and other artiodactyls of Savannah. This makes the sequence changes in 513 giraffe LWS opsin rather interesting and poses challenge in applying conventional 514 ecological arguments to the finding. Although the expected magnitude of $\lambda_{\max }$ 515 variation caused by the A180S is quite small $(\sim 5 \mathrm{~nm})$, the presence of an additional 516 change at site 233 located in TM5 of L-opsin suggests that the gene is under 517 differential selective pressure in giraffe. Since polymorphisms in human OPN1LW are 518 likely adaptive (Verrelli \& Tishkoff, 2004; Verrelli et al., 2008), it is reasonable to 519 also postulate on selection drivers acting on $O P N 1 L W$ in the giraffe.

520 Mitchell et al. (2013) and others have speculated that giraffe height and extraordinary 521 visual capacity may have co-evoluted. Gradual acquisition of long necks may have 522 provided giraffes with selective ability to see predators from afar, besides the feeding 523 advantage for nutritious and top placed foliage (Mitchell \& Skinner, 2003; Williams, 524 2016). Indeed, because of their excellent aerial vision, adult giraffes are rarely killed 525 by lions (Periquet et al., 2012; Strauss \& Packer, 2013). But giraffe height advantage 526 to see lions from afar likely presents challenges in identifying camouflaged lions in 527 the background of tall dry grass of the semi-arid Savannah. This probably explains the 528 overrepresentation of giraffes among lion kills during the arid season (Owen-Smith, 529 2008; Davidson et al., 2013). Therefore, sequence changes in giraffe's L-cone pigment 530 could be an adaptive response to predation pressure that provides giraffes with 
531 differential spectral mechanisms for enhanced ability to discriminate between dry

532 savannah vegetation and lions.

533 The alternative explanation is intra-specific communication among giraffe 534 populations. Among major giraffe populations, the characteristic pelage color is 535 reddish-brown spots separated by variable network of fine white lines (Brown et al., 536 2007; Fennessy et al., 2016). In fish, avian and other mammal species, patches of 537 color on the face or tails are clearly for communication purpose with conspecifics 538 (Caro, 2005; Price et al., 2008; Stoddard \& Prum, 2011). Since various giraffe 539 subspecies exhibit polymorphisms in pelage pattern and often have overlapping home 540 ranges, it is thought that one of the ways giraffes maintain reproductive isolation in 541 the wild is through pelage-based mate discrimination (Brown et al., 2007). Thus, one 542 might think that spectral tuning of the giraffe visual pigments should also match with 543 characteristic color of conspecifics and allow for easy recognition among giraffes. 544 Accordingly, giraffe's L-cone pigment might possess a slightly red-shifted $\lambda_{\max }$ to 545 enable sharp detection of conspecifics for several purposes, including preferred mate 546 choices.

547 At the present time there shouldn't be a priori reasoning that one or the other 548 argument is a correct explanation of the actual significance of adaptive evolution in 549 giraffe or okapi vision genes. For example, there is currently no evidence on whether 550 sequence changes in giraffe's L-cone pigment contribute sufficiently or not in 551 conferring variation in the ability to detect predators or discriminate conspecifics. 552 Direct evidence to support these speculations necessarily requires studies linking 553 sequence evolution to functional changes. Towards this goal, first, the fixation status 554 of the sequence changes needs to be clarified among giraffe and okapi populations. 555 Secondly, a combination of divergence-based and population genetics approaches is 556 potentially suited to ascertain the adaptive consequences of selection divergence 557 (Verrelli et al., 2008). Finally, definitive link between sequence changes and 558 adaptation require ecological and comparative studies on giraffe and okapi visual 559 behaviors. 


\section{Conclusions}

561 Subset of genes known to play functional role in vision has been analyzed in order to 562 identify if remarkable differences in vision between giraffe and okapi is associated 563 with adaptive evolution. The finding that visual genes are highly conserved in their 564 evolution signifies strong purifying selection in giraffe and okapi visual genes. 565 Putative evidence of positive selection and selection divergence is observed on few 566 candidate vision genes in both giraffe and okapi. Signature of selection in genes 567 functionally associated with important optical elements of the eye, such as the cornea, 568 the lens and the retina, could be indicative of concerted, organ-level impact of natural 569 selection in adjusting species' vision to their respective environment. This 570 demonstrate the importance of system-level understand of molecular evolution 571 associated with complex traits (Invergo et al., 2013). We believe that comparative 572 evolutionary vision studies such as this could contribute to the understanding of the 573 molecular genetic system underlying vision in mammals in general. 
574 Figure 1. Positive selection in $L U M$ is predicted to have occurred in okapi (adapted to deep575 forest) when compared to other ruminants inhabiting light illuminated environment. (A) PhyML 576 generated maximum likelihood $L U M$ gene tree that was used in branch-site test for positive 577 selection setting okapi as a foreground lineage. (B) LUM protein alignment showing positions at 578 which okapi differ with species within ruminant, cetacean, equine and pig families. Conserved 579 positions are omitted from the alignment. The codon position predicted to have undergone 580 positive selection is color highlighted at site 36 which encodes a unique amino acid in okapi 581 compared with other species in the alignment. (C) Vertebrate-wide evolution at codon 36 shows 582 signature of convergent evolution between okapi and Malayan colugo (Galeopterus variegatus). 583 The identity of codon at the predicted positive selection site and the respective amino acid (in 584 bracket) are shown for each of the terminal species and for some ancestral lineages. 
(A)

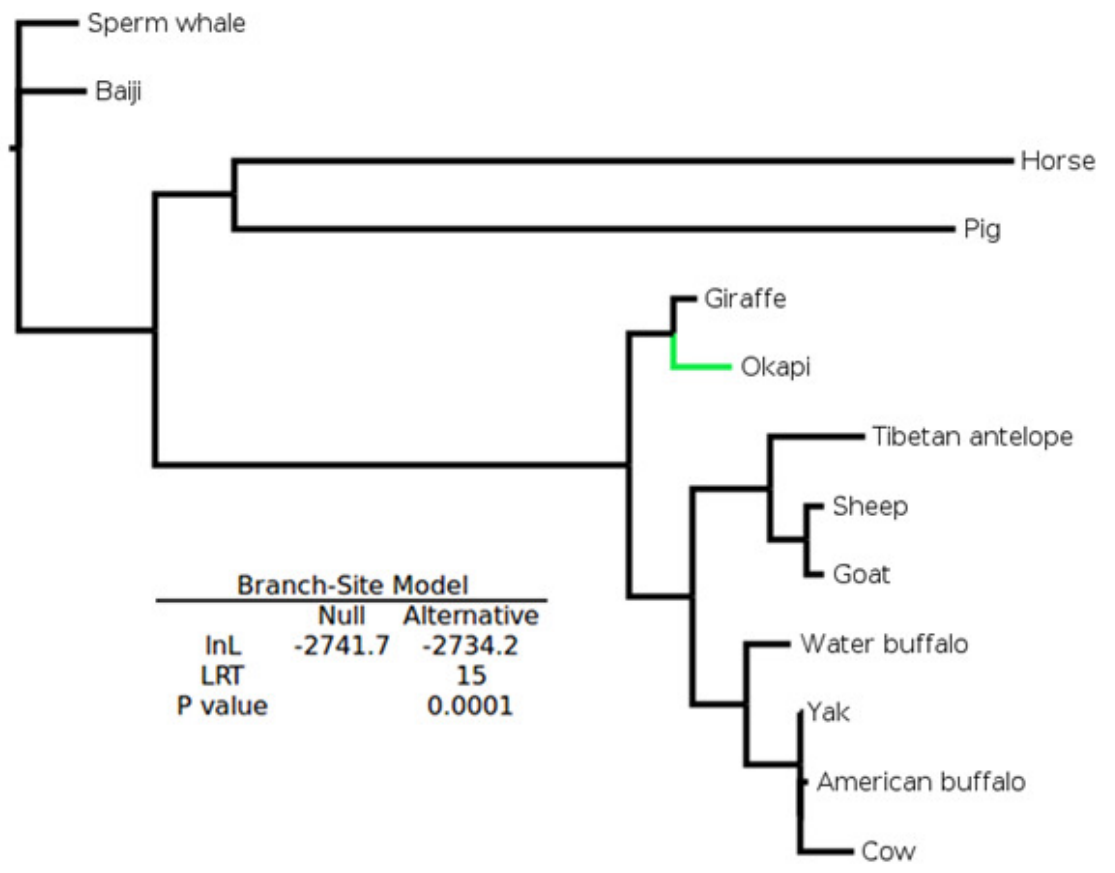

(B)

11111111111222222222222223333

1111112222222233335678912455668888000013334455791224 235782456891234578912363407749104780459013501344807249022

Okapi NLVPLLGSASTLDYYDYSFQSIATTPEQRYKNSFIVLKSMTLSSRSAESVVSDRIQN NLVPLLGRASTLDYYDYSFOSIRTTPEQRYKNSFIVLKSMTLSSRSAESVVSDRIQN Cow NLVPLLGGASTPDYYEYDFQALRSSPDQKYKNSFIVLKSMTLSSRSAESVVSDHIQN Yak NLVPLLGGASTPDYYDYDFQPMR SSPDQKYKNSFIVLKSMTLSSRSAESVVSDHIQN Water buffalo NLVPLLGGASTLDYYDYDFQSIRSSPDQKYKNSFIVLKSMTLSTRSAESVVSDHIQN American buffalo NLVPLLGGASTPDYYDYDFQPMR SSPDQKYKNSF IVLKSMTLSSRSAESVVSDHIQN NLVPLLGGASTPDYYDYDFQSIRITSPEORYKHSF IVLKSMTLSSRSAE SVYSDHION Tibetan antelope NLVPLLGGASTPDYYDYDFQSIRTSPEQKYKHSFIVLKSMTLSSRSAESVVNDHIQN Goat

Pig

Sperm whale Baiji NLVPLLGGASTPDYYDYDFQSIRTSPEQRYKHSF IVLKSITLSSRSAESVVSDHIQN HLVTLTGSAGHYDDDDY - FLS IRITSPDERYKNSF IVFRGMTLSSHSGESI LNER IQN NLMPLLGCAGSY - YEDD - FLSIRTSLDQKYKNSFIVFKSMTMSSRSGESIVNER IQN NLMPLLGCAGSY - YEDD - FLSIRTSLDQKYKNSF IVFRSMTMSSRNGASIVNER IQN Horse NPATFLSGTGYYDDYDN - I LS I RTSPEQRHRHTMVI FRSMSLTSRNGEG I VNERLHT

(C)

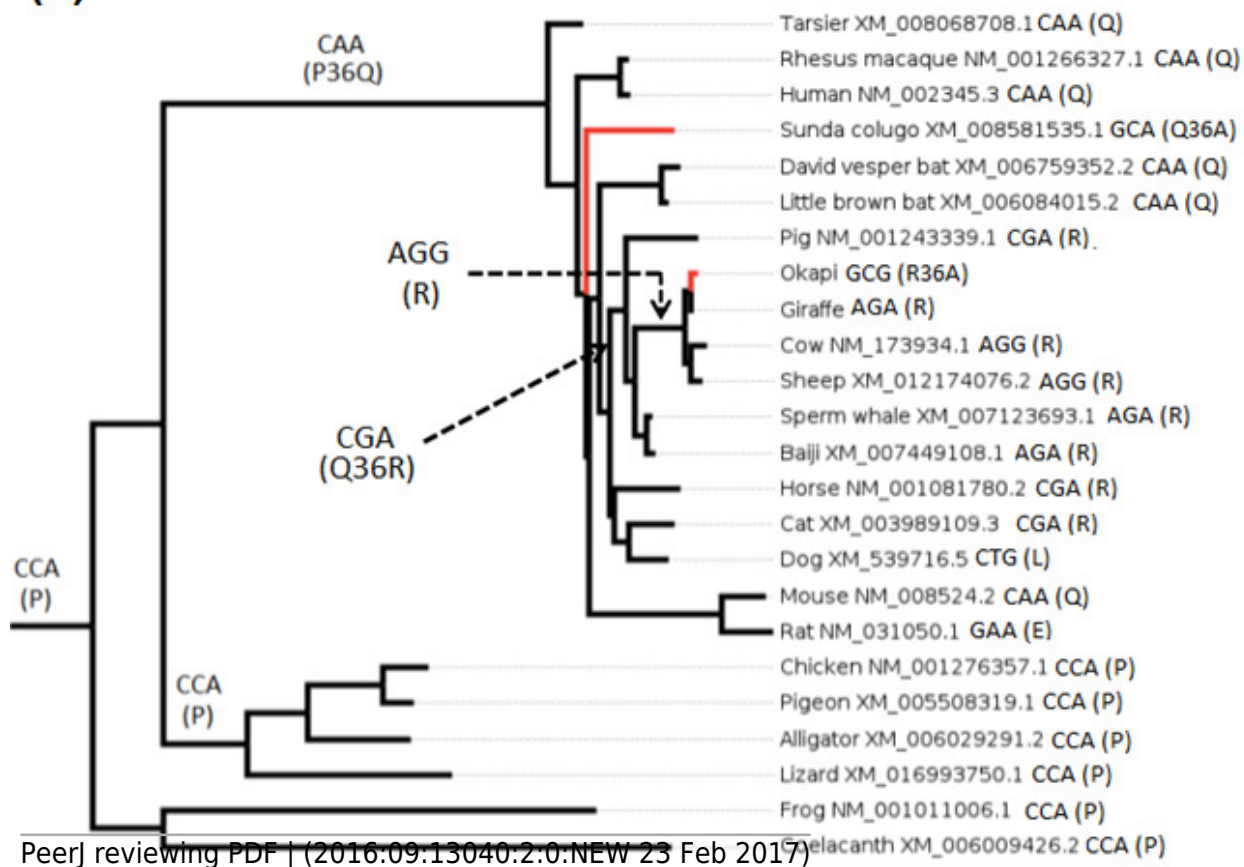


587 Figure 2. Gene trees and substitution analysis indicating sites (highlighted in red) potentially 588 contributing to selection divergence in $S A G, C R Y A A$ and OPN1LW. The $\omega$ ratio for each 589 variant site in the three genes was computed using the site-wise likelihood ratio analysis 590 (Massingham \& Goldman, 2005). (A) $S A G$ has five sites which show signature of differential 591 selection between okapi and other ruminants. (B) $C R Y A A$ has several sites which exhibit 592 signature of selection but the associated sequence changes in giraffe are shared with okapi. (C) 593 Substitution analysis shows seven variant sites (4, 8, 170, 171, 180, 233 and 236) which differ 594 between giraffe and any ruminant species shown in the phylogeny. Variant sites 180 and 233 595 have Bayes posterior probability of 0.93 and 0.89 respectively. All giraffe's sequences were 596 found to be identical between NZOO and MA1 (Agaba et al., 2016) verifying that the identified 597 substitutions are not artifacts. (D) The ribbon diagram of giraffe L-opsin highlighting important 598 sequence changes relative to its secondary structure. Its spectrally important amino acids based 599 on the five-sites rule are highlighted in yellow. A threonine at amino site 233 with respect to its 600 unique S233T among ruminants is highlighted in green. The ribbon plot for the OPN1LW was 601 generated by Protter (Omasits et al., 2013). 
(A)
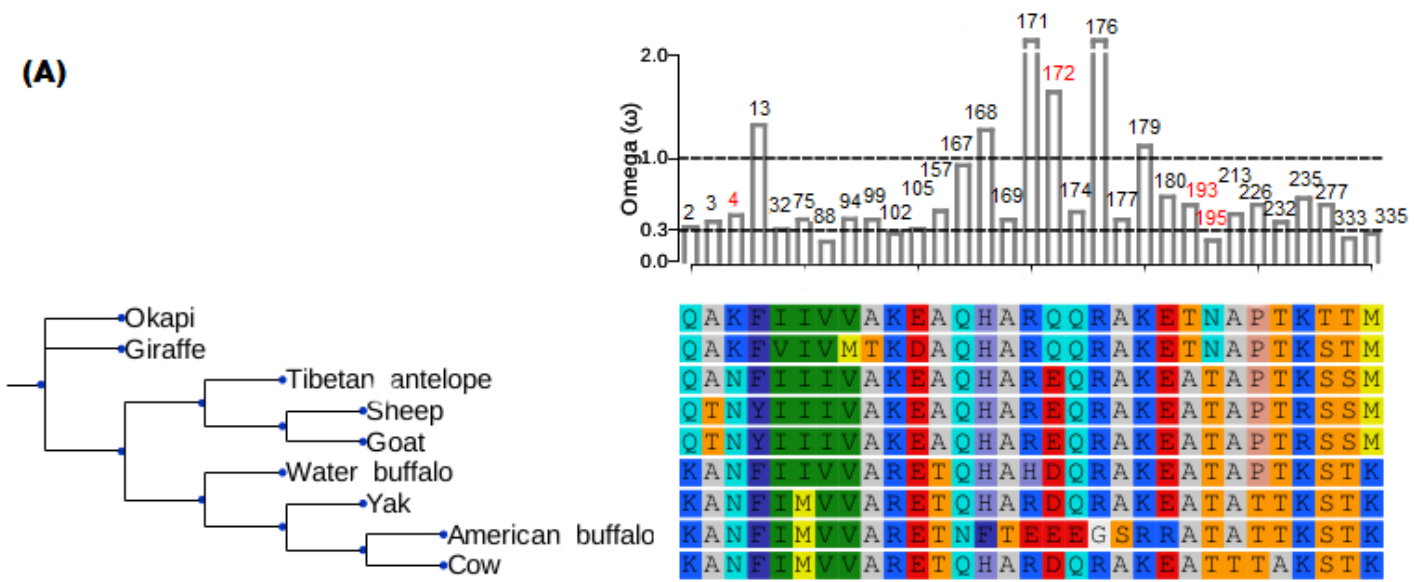

(B)

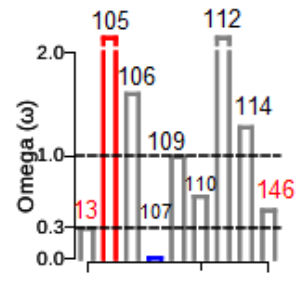

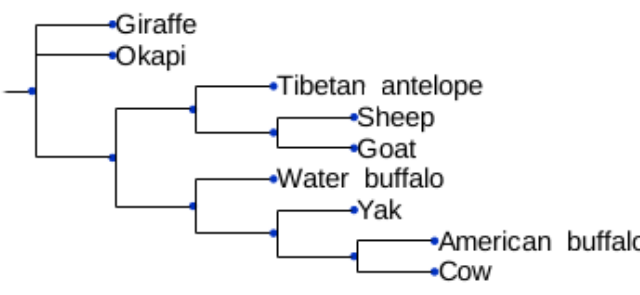

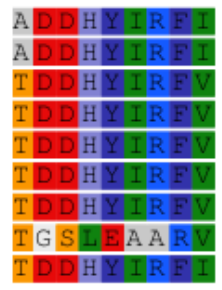

(C)
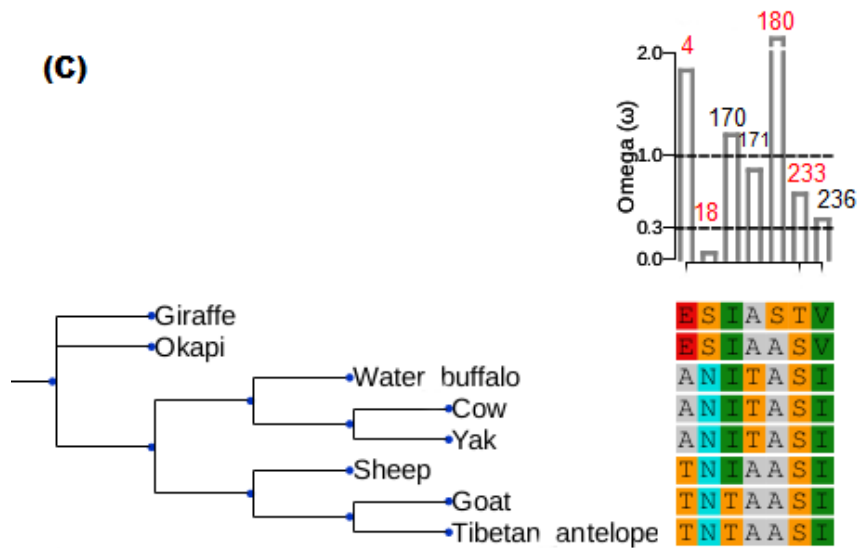

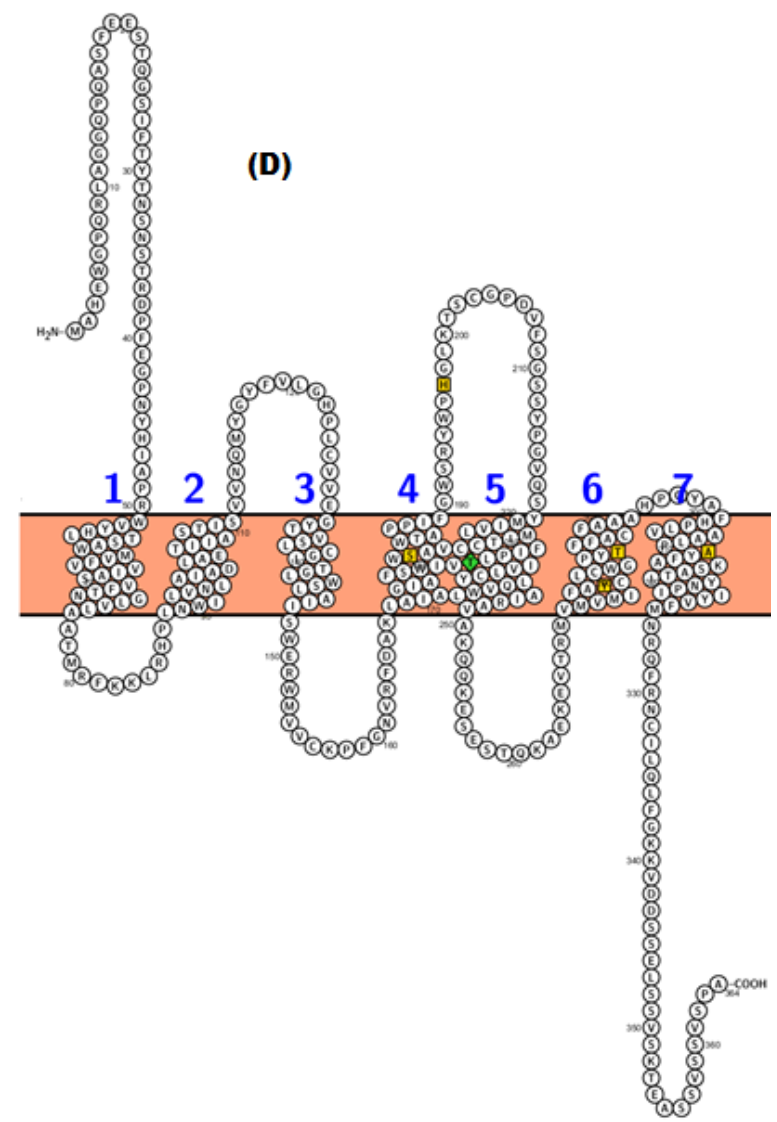


605

606 Figure 3. The evolutionary relationship in mammals based on OPN1LW as revealed by coding 607 gene sequences. For species whose sequences were obtained from public database Refseq or 608 Genbank accession numbers for the respective sequences are shown. 
C Green monkey XM_007993132.1

Rhesus macaque XM_015128550.1

L Crab-eating macaque AF158968.1

Baboon NM_001168797.1

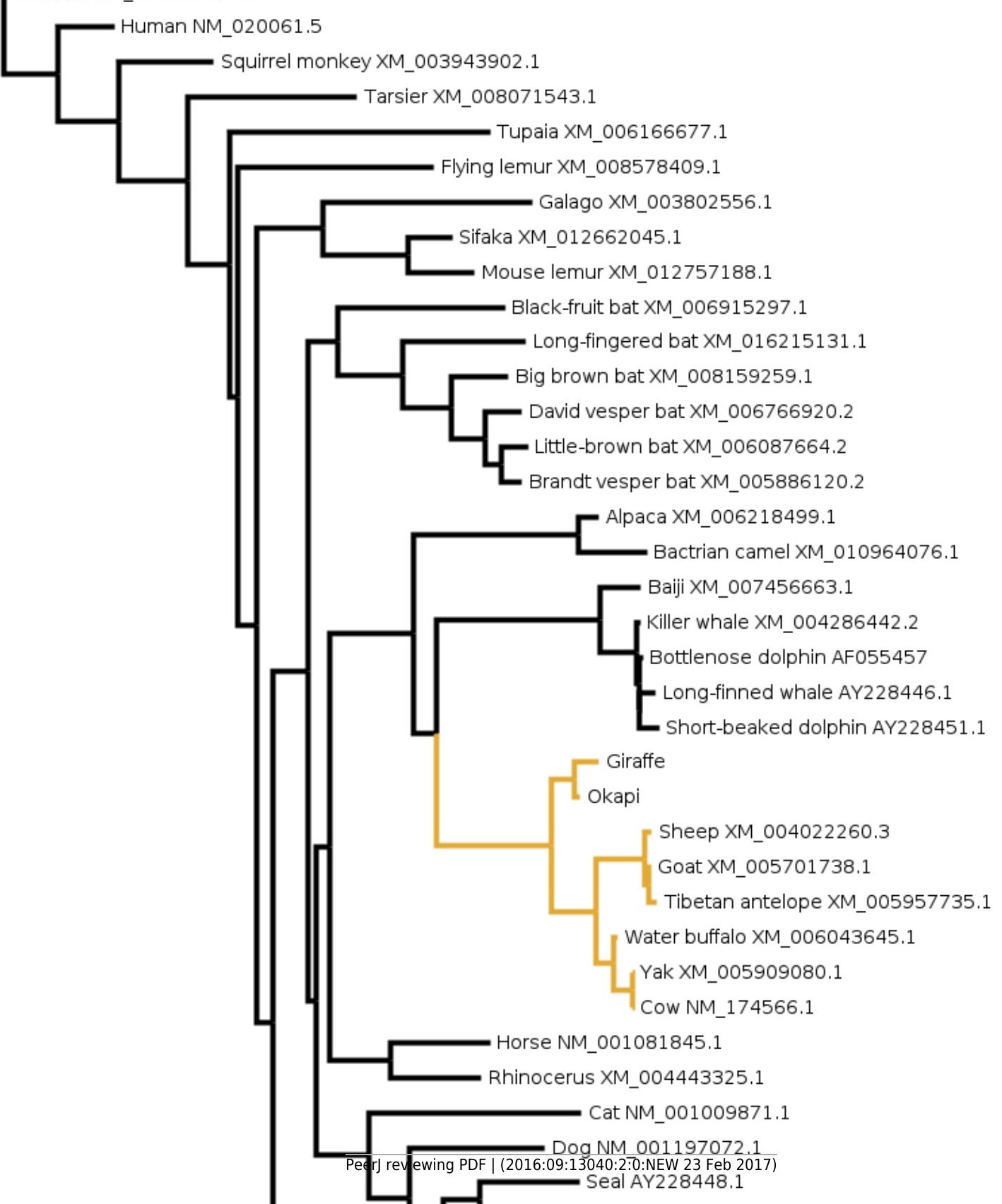


three vision genes between giraffe or okapi (Clade 1) against the background of ruminant species (Clade 0)

\begin{tabular}{|c|c|c|c|c|c|c|c|c|c|c|c|c|c|}
\hline & \multicolumn{7}{|c|}{ Giraffe } & \multicolumn{6}{|c|}{ Okapi } \\
\hline & \multicolumn{2}{|c|}{$\ln L$} & & \multicolumn{3}{|c|}{ Site classes } & \multirow[b]{2}{*}{$P$-value } & \multirow{2}{*}{\begin{tabular}{|l}
$\operatorname{lnL}$ \\
$\mathrm{CmC}$
\end{tabular}} & \multirow[b]{2}{*}{ LRT } & \multicolumn{3}{|c|}{ Site classes } & \\
\hline Gene & M2a_rel & $\mathrm{CmC}$ & LRT & 0 & 1 & 2 & & & & 0 & 1 & 2 & P-value \\
\hline$C R Y A A$ & -936.5 & -933.8 & 5.3 & $\begin{array}{l}P_{0}=0.9 \\
\omega_{0}=0.0\end{array}$ & $\begin{array}{l}P_{1}=0.0 \\
\omega_{1}=1\end{array}$ & $\begin{array}{l}P_{2}=0.1 \\
\omega_{\text {Clade } 0}=1.4 \\
\omega_{\text {Clade } 1}=0.0\end{array}$ & 0.02 & -935.1 & 2.8 & $\begin{array}{l}P_{0}=0.9 \\
\omega_{0}=0.0\end{array}$ & $\begin{array}{l}P_{1}=0.0 \\
\omega_{1}=1\end{array}$ & $\begin{array}{l}P_{2}=0.1 \\
\omega_{\text {Clade } 0}=1.2 \\
\omega_{\text {Clade } 1}=0.0\end{array}$ & 0.09 \\
\hline$S A G$ & -2177.5 & -2176.8 & 1.6 & $\begin{array}{l}P_{0}=0.4 \\
\omega_{0}=0.05\end{array}$ & $\begin{array}{l}P_{1}=0.1 \\
\omega_{1}=1\end{array}$ & $\begin{array}{l}P_{2}=0.5 \\
\omega_{\text {Clade } 0}=0.5 \\
\omega_{\text {Clade } 1}=0.2\end{array}$ & 0.2 & -2175.5 & 4.1 & $\begin{array}{l}P_{0}=0.95 \\
\omega_{0}=0.08\end{array}$ & $\begin{array}{l}P_{1}=0.0 \\
\omega_{1}=1\end{array}$ & $\begin{array}{l}P_{2}=0.05 \\
\omega_{\text {Clade } 0}=0.0 \\
\omega_{\text {Clade } 1}=2.3\end{array}$ & 0.04 \\
\hline OPN1LW & -1780.6 & -1778.2 & 4.7 & $\begin{array}{l}P_{0}=0.96 \\
\omega_{0}=0.0\end{array}$ & $\begin{array}{l}P_{1}=0.03 \\
\omega_{1}=1\end{array}$ & $\begin{array}{l}P_{2}=0.01 \\
\omega_{\text {Clade 0 }}=0.0 \\
\omega_{\text {Clade } 1}=339.6\end{array}$ & 0.03 & -1780.2 & 0.7 & $\begin{array}{l}P_{0}=0.95 \\
\omega_{0}=0.0\end{array}$ & $\begin{array}{l}P_{1}=0.0 \\
\omega_{1}=1\end{array}$ & $\begin{array}{l}P_{2}=0.05 \\
\omega_{\text {Clade } 0}=0.9 \\
\omega_{\text {Clade } 1}=0.0\end{array}$ & 0.4 \\
\hline
\end{tabular}


616 Table 2. Identity of amino acids at the functionally important sites in the L-opsin of giraffe and other mammals based on the five-sites rule. For each species, the expected $\lambda_{\max }$ based on the five-site rule is shown. Where the actual $\lambda_{\max }$ of the pigment has been determined, the value is indicated.

\begin{tabular}{|c|c|c|c|c|c|c|c|c|}
\hline \multirow[b]{3}{*}{ Species } & \multicolumn{5}{|c|}{ Site/amino acid } & \multirow[b]{3}{*}{ Predicted $\lambda_{\max }(\mathrm{nm})$} & \multirow[b]{3}{*}{ Experimental $\lambda_{\max }(\mathrm{nm})$} & \multirow[b]{3}{*}{ References } \\
\hline & 180 & 197 & 277 & 285 & 308 & & & \\
\hline & & & & & & & & \\
\hline Human (Homo sapiens) & $\mathrm{S}$ & $\mathrm{H}$ & $\mathrm{Y}$ & $\mathrm{T}$ & A & 560 & 557 & Merbs \& Nathans, 1992 \\
\hline Human (H. sapiens) & A & $\mathrm{H}$ & $\mathrm{Y}$ & $\mathrm{T}$ & A & 553 & 552 & Merbs \& Nathans, 1992 \\
\hline Rhesus macaque (Macaca mulatta) & $\mathrm{S}$ & $\mathrm{H}$ & $\mathrm{Y}$ & $T$ & A & 560 & 561.5 & Bowmaker et al., 1991 \\
\hline Crab-eating macaque (Macaca fascicularis) & $\mathrm{S}$ & $\mathrm{H}$ & $\mathrm{Y}$ & $\mathrm{T}$ & A & 560 & 561 & Baylor, Nunn \& Schnapft, 1 \\
\hline Baboon (Papio anubis) & $\mathrm{S}$ & $\mathrm{H}$ & $\mathrm{Y}$ & $\mathrm{T}$ & $A$ & 560 & 560 & Bowmaker et al., 1991 \\
\hline Green monkey (Chlorocebus sabaeus) & $\mathrm{S}$ & $\mathrm{H}$ & $\mathrm{Y}$ & $\mathrm{T}$ & A & 560 & - & \\
\hline Seal (Phoca vitulina) & $\mathrm{S}$ & $\mathrm{H}$ & $\mathrm{F}$ & $\mathrm{T}$ & A & 552 & 510 (?) & Crognale et al., 1998; Lever \\
\hline Walrus (Odobenus rosmarus) & $\mathrm{S}$ & $\mathrm{H}$ & $\mathrm{Y}$ & $\mathrm{T}$ & A & 560 & - & \\
\hline Brandt's vesper bat (Myotis brandtii) & $\mathrm{S}$ & $\mathrm{H}$ & $\mathrm{Y}$ & $\mathrm{T}$ & A & 560 & - & \\
\hline David's vesper bat (Myotis davidii) & $\mathrm{S}$ & $\mathrm{H}$ & $\mathrm{Y}$ & $\bar{T}$ & A & 560 & - & \\
\hline Big brown bat (Epistesicus fuscus) & $\mathrm{S}$ & $\mathrm{H}$ & $\mathrm{Y}$ & $\mathrm{T}$ & A & 560 & - & \\
\hline Little brown bat (Myotis lucifugus) & $\mathrm{S}$ & $\mathrm{H}$ & $\mathrm{Y}$ & $\mathrm{T}$ & A & 560 & - & \\
\hline Cow (Bos taurus) & A & $\mathrm{H}$ & $\mathrm{Y}$ & $\mathrm{T}$ & A & 553 & 555 & Jacobs et al., 1998 \\
\hline Sheep (Ovis aries) & A & $\mathrm{H}$ & $\mathrm{Y}$ & $\mathrm{T}$ & A & 553 & 552 & Jacobs et al., 1998 \\
\hline Goat (Capra hircus) & A & $\mathrm{H}$ & $\mathrm{Y}$ & $\mathrm{T}$ & A & 553 & 553 & Jacobs et al., 1998 \\
\hline Giraffe (Giraffa camelopardalis) & $\mathrm{S}$ & $\mathrm{H}$ & $\mathrm{Y}$ & $\mathrm{T}$ & A & 560 & - & \\
\hline Okapi (Okapia johnstonii) & $A$ & $\mathrm{H}$ & $\mathrm{Y}$ & $\mathrm{T}$ & $A$ & 553 & - & \\
\hline
\end{tabular}


620

621

622

623

624

625

626

627

628

629

630

631

632

633

634

635

636

637

638

639

640

641

642

643

644

645

646

647

648

649

650

651

652

653

\section{References}

Agaba M., Ishengoma E., Miller WC., Mcgrath BC., Hudson CN., Reina OCB., Ratan A., Burhans R., Chikhi R., Medvedev P., Praul CA., Wu-cavener L., Wood B., Robertson H., Penfold L., Cavener DR. 2016. Giraffe genome sequence reveals clues to its unique morphology and physiology. Natare Communications 7:1-8. DOI: 10.1038/ncomms11519.

Austin BA., Coulon C., Liu CY., Kao WWY., Rada JA. 2002. Altered collagen fibril formation in the sclera of lumican-deficient mice. Investigative Ophthalmology and Visual Science 43:1695-1701.

Baylor DA., Nunn BJ., Schnapft JL. 1987. Spectral Sensitivity of Cones of the Monkey Macaca fascicularis. Journal of Physiology 390:145-160.

Benson DA., Cavanaugh M., Clark K., Karsch-mizrachi I., Lipman DJ., Ostell J., Sayers EW. 2013. GenBank. Nucleic Acids Research 41:D36-D42. DOI: 10.1093/nar/gks1195.

Bielawski JP., Yang Z. 2004. A Maximum Likelihood Method for Detecting Functional Divergence at Individual Codon Sites, with Application to Gene Family Evolution. Journal of Molecular Evolution 59:121-132. DOI: 10.1007/s00239-004-2597-8.

Blochberger TC., Vergnes J., Hempel J., Hassell JR. 1992. cDNA to Chick Lumican (Corneal Keratan Sulfate Proteoglycan) Reveals Homology to the Small Interstitial Proteoglycan Gene Family and Expression in Muscle and Intestine. The Journal of Biological Chemistry 267:347-352.

Bowmaker JK. 2008. Evolution of vertebrate visual pigments. Vision research 48:2022-41. DOI: 10.1016/j.visres.2008.03.025.

Bowmaker JK., Astell S., Hunt DM., Mollon JD. 1991. Photosensitive and Photostable Pigments in the Retinae of Old World Monkeys. Journal of Experimental Biology 156:1-19.

Brown DM., Brenneman RA., Koepfli K., Pollinger JP., Milá B., Georgiadis NJ., Jr EEL., Grether GF., Jacobs DK., Wayne RK., Louis EE., Grether GF., Jacobs DK. 2007. Extensive population genetic structure in the giraffe. BMC Biology 13:1-13. DOI: 10.1186/17417007-5-57.

Caro T. 2005. The Adaptive Significance of Coloration in Mammals. BioScience 55:125-136. DOI: 10.1641/0006-3568(2005)055[0125:TASOCI]2.0.CO;2.

Cepko C. 2014. Intrinsically different retinal progenitor cells produce specific types of progeny. Nature Reviews Neuroscience 15:615-627. DOI: 10.1038/nrn3767.

Chakravarti S., Magnuson T., Lass JH., Jepsen KJ., Lamantia C., Carroll H. 1998. Lumican Regulates Collagen Fibril Assembly: Skin Fragility and Corneal Opacity in the Absence of Lumican. The Journal of Cell Biology 141:1277-1286. 
654 Chakravarti S., Paul J., Roberts L., Chervoneva I., Oldberg A., Birk DE. 2003. Ocular and scleral 655 alterations in gene-targeted lumican-fibromodulin double-null mice. Investigative 656 Ophthalmology and Visual Science 44:2422-2432. DOI: 10.1167/iovs.02-0783.

657 Chakravarti S., Petroll WM., Hassell JR., Jester J V., Lass JH., Paul J., Birk DE. 2000. Corneal 658 Opacity in Lumican-Null Mice: Defects in Collagen Fibril Structure and Packing in the 659 Posterior Stroma. Investigative Ophthalmology \& Visual Science 41:3365-3373.

660

661

662

663

664

665

666

667

668

669

670

671

672

673

674

675

676

677

678

679

680

681

682

683

684

685

686

687

Collin SP., Davies WL., Hart NS., Hunt DM. 2009. The evolution of early vertebrate photoreceptors. Philosophical Transactions of the Royal Society B 364:2925-2940. DOI: 10.1098/rstb.2009.0099.

Crognale MA., Levenson DH., Ponganis PJ., Deegan JF., Jacobs GH 1998. 1998. Cone spectral sensitivity in the harbor seal (Phoca vitulina) and implications for color vision. Canadian Journal of Zoology 76:2114-2118.

Davidson Z., Valeix M., Van Kesteren F., Loveridge AJ., Hunt JE., Murindagomo F., Macdonald DW. 2013. Seasonal Diet and Prey Preference of the African Lion in a Waterhole-Driven Semi-Arid Savanna. PLoS ONE 8:e55182. DOI: 10.1371/journal.pone.0055182.

Dimitrova M., Merilaita S. 2010. Prey concealment : visual background complexity and prey contrast distribution. Behavioral Ecology 21:176-181. DOI: 10.1093/beheco/arp174.

Douglas RH., Jeffery G. 2014. The spectral transmission of ocular media suggests ultraviolet sensitivity is widespread among mammals. Proceedings of Royal Society B 281:20132995.

Edgar RC. 2004. MUSCLE: multiple sequence alignment with high accuracy and high throughput. Nucleic Acids Research 32:1792-1797. DOI: 10.1093/nar/gkh340.

Fennessy J., Bidon T., Reuss F., Vamberger M., Fritz U., Kumar V., Elkan P., Nilsson MA., Janke A. 2016. Multi-locus Analyses Reveal Four Giraffe Species Instead of One. Current Biology 26:1-7. DOI: 10.1016/j.cub.2016.07.036.

Flicek P., Ahmed I., Amode MR., Barrell D., Beal K., Brent S., Carvalho-silva D., Clapham P., Coates G., Fairley S., Gordon L., Hourlier T., Fitzgerald S., Gil L., Garc1 C., Keenan S., Hunt S., Juettemann T., Ka AK., Komorowska M., Kulesha E., Longden I., Maurel T., Mclaren WM., Muffato M., Nag R., Overduin B., Pignatelli M., Pritchard B., Pritchard E., Riat HS., Ritchie GRS., Ruffier M., Schuster M., Sheppard D., Sobral D., Taylor K., Thormann A., Trevanion S., White S., Wilder SP., Aken BL., Birney E., Cunningham F., Dunham I., Harrow J., Herrero J., Hubbard TJP., Johnson N., Kinsella R., Parker A., Spudich G., Yates A., Zadissa A., Searle SMJ. 2012. Ensembl 2013. Nucleic Acids Research 41:D48-D55. DOI: 10.1093/nar/gks1236. 
688 Fuchs S., Nakazawa M., Maw M., Tamai M., Oguchi Y., Gal A. 1995. A homozygous 1-base 689 pair deletion in the arrestin gene is a frequent cause of Oguchi disease in Japanese. Nature $690 \quad$ Genetics 10:360-362.

691 Greive BT., Iwago M. 2003. Priceless: The Vanishing Beauty of A Fragile Planet. Andrews 692 McMeel Publishing.

693 Griebel U., Peichl L. 2003. Colour vision in aquatic mammals — facts and open questions. $694 \quad$ Aquatic Mammals 29:18-30.

695 Guindon S., Gascuel O. 2003. A Simple, Fast, and Accurate Method to Estimate Large 696 Phylogenies by Maximum Likelihood. Systematic Biology 52:696-704. DOI: $697 \quad 10.1080 / 10635150390235520$.

698 Heesy CP., Hall MI. 2010. The nocturnal bottleneck and the evolution of mammalian vision. 699 Brain, Behavior and Evolution 75:195-203. DOI: 10.1159/000314278. 
700

701

702

703

704

705

706

707

708

709

710

711

712

713

714

715

716

717

718

719

720

721

722

723

724

725

726

727

728

729

730

731

732

Hendriks W., Leunissen J., Nevo E., Bloemendal H., De Jong WW. 1987. The lens protein aAcrystallin of the blind mole rat, Spalax ehrenbergi: Evolutionary change and functional constraints. Proceedings of the National Academy of Science USA 84:5320-5324. DOI: 10.1073/pnas.84.15.5320.

Hirano T., Imai H., Kandori H., Shichida Y. 2001. Chloride Effect on Iodopsin Studied by LowTemperature Visible and Infrared Spectroscopies. Biochemistry 40:1385-1392.

Hofmann CM., O’Quin KE., Justin Marshall N., Cronin TW., Seehausen O., Carleton KL. 2009. The eyes have it: Regulatory and structural changes both underlie cichlid visual pigment diversity. PLoS Biology 7:e1000266. DOI: 10.1371/journal.pbio.1000266.

Hofmann CM., O'Quin KE., Justin Marshall N., Carleton KL. 2010. The relationship between lens transmission and opsin gene expression in cichlids from Lake Malawi. Vision Research 50:357-363. DOI: 10.1016/j.visres.2009.12.004.

Honkavaara J., Koivula M., Korpima E., Siitari H., Viitala J. 2002. Ultraviolet vision and foraging in terrestrial vertebrates. Oikos 98:505-511.

Horth L. 2007. Sensory genes and mate choice: Evidence that duplications, mutations, and adaptive evolution alter variation in mating cue genes and their receptors. Genomics 90:159-175. DOI: 10.1016/j.ygeno.2007.03.021.

Hunt D., Carvalho LS., Cowing JA., Davies WL. 2009. Evolution and spectral tuning of visual pigments in birds and mammals. Philosophical Transactions of the Royal Society B 364:2941-2955. DOI: 10.1098/rstb.2009.0044.

Invergo BM., Montanucci L., Laayouni H., Bertranpetit J. 2013. A system-level, molecular evolutionary analysis of mammalian phototransduction. BMC Evolutionary Biology 13:52.

Jacobs GH., Jess F Deegan II., Neitz J. 1998. Photopigment basis for dichromatic color vision in cows, goats, and sheep. Visual Neuroscience 15:581-584.

Jacobs GH. 2009. Evolution of colour vision in mammals. Philosophical Transactions of the Royal Society B 364:2957-2967. DOI: 10.1098/rstb.2009.0039.

Jeon C., Strettoi E., Masland RH. 1998. The Major Cell Populations of the Mouse Retina. The Journal of Neuroscience 18:8936-8946.

Kalamajski S., Oldberg Å. 2009. Homologous Sequence in Lumican and Fibromodulin Leucinerich Repeat 5 - 7 Competes for Collagen Binding. The Journal of Biological Chemistry 284:534-539. DOI: 10.1074/jbc.M805721200.

Kawamura S. 2016. Color vision diversity and significance in primates inferred from genetic and field studies. Genes and Genomics 38:779-791. DOI: 10.1007/s13258-016-0448-9. 
733 Keen T., Inglehearn CF. 1996. Mutations and polymorphisms in the human peripherin-RDS gene

734

735

736

737

738

739

740

741

742

743

744

745

746

747

748

749

750

751

752

753

754

755

756

757

758

759

760

761

762

763

764

765 and their involvement in inherited retinal degeneration. Human Mutation 8:297-303.

Kirk EC., Kay RF. 2004. The Evolution of High Visual Acuity in the Anthropoidea. In: Anthropoid Origins. Springer US, 539-602.

Kohn A. 2007. Visual adaptation: physiology, mechanisms, and functional benefits. Journal of Neurophysiology 97:3155-3164. DOI: 10.1152/jn.00086.2007.

Kraft TW., Neitz J., Neitz M. 1998. Spectra of human L cones. Vision Research 38:3663-3670. DOI: 10.1016/S0042-6989(97)00371-4.

Kuhn H., Hall SW., Wilden U. 1984. Light-induced binding of 48- kDa protein to photoreceptor membranes is highly enhanced by phosphorylation of rhodopsin. FEBs Letters 176:473478.

Lamb BTD. 2011. Evolution of the Eye. Scientific American 305:64-69.

Larhammar D., Nordstrom K., Larsson TA. 2009. Evolution of vertebrate rod and cone phototransduction genes. Philosophical Transactions of the Royal Society B 364:28672880. DOI: $10.1098 /$ rstb.2009.0077.

Levenson DH., Ponganis PJ., Crognale MA., II JFD., Dizon A., Jacobs GH. 2006. Visual pigments of marine carnivores: pinnipeds, polar bear, and sea otter. Journal of Comparative Physiology A 192:833-843. DOI: 10.1121/1.4929899.

Lind O., Mitkus M., Olsson P., Kelber A. 2014. Ultraviolet vision in birds: the importance of transparent eye media. Proceedings of Royal Society B 281:20132209. DOI: 10.1098/rspb.2013.2209.

Lindsey SL., Green MN., Bennett CL. 1999. The Okapi: Mysterious Animal of Congo-Zaire. University of Texas Press.

Litt M., Kramer P., Lamorticella DM., Murphey W., Lovrien EW., Weleber RG. 1998. Autosomal dominant congenital cataract associated with a missense mutation in the human alpha crystallin gene CRYAA. Human Molecular Genetics 7:471-474.

Lythgoe JN. 1984. Visual pigments and environmental light. Vision Research 24:1539-1550.

Massingham T., Goldman N. 2005. Detecting Amino Acid Sites Under Positive Selection and Purifying Selection. Genetics 169:1753-1762. DOI: 10.1534/genetics.104.032144.

Matsumoto Y., Hiramatsu C., Matsushita Y., Ozawa N., Ashino R., Nakata M., Kasagi S., Di Fiore A., Schaffner CM., Aureli F., Melin AD., Kawamura S. 2014. Evolutionary renovation of $\mathrm{L} / \mathrm{M}$ opsin polymorphism confers a fruit discrimination advantage to ateline New World monkeys. Molecular Ecology 23:1799-1812. DOI: 10.1111/mec.12703. 
766

767

768

769

770

771

772

773

774

775

776

777

778

779

780

781

782

783

784

785

786

787

788

789

790

791

792

793

794

795

796

797

798

Meek KM., Knupp C. 2015. Corneal structure and transparency. Progress in Retinal and Eye Research 49:1-16. DOI: 10.1016/j.preteyeres.2015.07.001.

Melin AD., Danosi CF., Mccracken GF., Dominy NJ. 2014. Dichromatic vision in a fruit bat with diurnal proclivities: the Samoan flying fox (Pteropus samoensis). Journal of Comparative Physiology A 200:1015-1022. DOI: 10.1007/s00359-014-0951-x.

Merbs SL., Nathans J. 1992. Absorption spectra of human cone pigments. Nature 356:433-435.

Merbs SL., Nathans J. 1993. Role of hydroxyl-bearing amino acids in differentially tuning the absorption spectra of the human red and green cone pigments. Photochemistry and Photobiology 58:706-710.

Mitchell G., Roberts DG., Sittert SJ Van., Skinner JD. 2013. Orbit orientation and eye morphometrics in giraffes (Giraffa camelopardalis). African Zoology 48:333-339.

Mitchell G., Skinner JD. 2003. On the origin, evolution and phylogeny of giraffes Giraffa camelopardalis. Transactions of the Royal Society of South Africa 58:51-73.

Morrison MA., Silveira AC., Huynh N., Jun G., Smith SE., Zacharaki F., Sato H., Loomis S., Andreoli MT., Adams SM., Radeke MJ., Jelcick AS., Yuan Y., Tsiloulis AN., Chatzoulis DZ., Silvestri G., Kotoula MG., Tsironi EE., Hollis BW., Chen R., Haider NB., Miller JW., Farrer LA., Hageman GS., Kim IK., Schaumberg DA., Deangelis MM. 2011. Systems biology-based analysis implicates a novel role for vitamin D metabolism in the pathogenesis of age-related macular degeneration. Human Genomics 5:538-568.

Nagaraj RH., Nahomi RB., Shanthakumar S., Linetsky M., Padmanabha S., Pasupuleti N., Wang B., Santhoshkumar P., Kumar A., Biswas A. 2012. Acetylation of $\alpha$ A-crystallin in the human lens: Effects on structure and chaperone function. Biochimica et Biophysica Acta 1822:120-129. DOI: 10.1016/j.bbadis.2011.11.011.

Nakazawa M., Wada Y., Tamai M. 1998. Arrestin Gene Mutations in Autosomal Recessive Retinitis Pigmentosa. Archive of Ophthalmology 116:498-501.

Nathans J., Hogness DS. 1983. Isolation, Sequence Analysis, and Intron-Exon Arrangement of the Gene Encoding Bovine Rhodopsin. Cell 34:807-814.

Omasits U., Ahrens CH., Mu S., Wollscheid B. 2013. Protter: interactive protein feature visualization and integration with experimental proteomic data. Bioinformatics 30:884-886. DOI: 10.1093/bioinformatics/btt607.

Osorio D., Vorobyev M. 2005. Photoreceptor spectral sensitivities in terrestrial animals: adaptations for luminance and colour vision. Proceedings of Royal Society B 272:17451752. DOI: $10.1098 / \mathrm{rspb} .2005 .3156$. 
799

800

801

802

803

804

805

806

807

808

809

810

811

812

813

814

815

816

817

818

819

820

821

822

823

824

825

826

827

828

829

830

831

832

Owen-Smith N. 2008. Changing vulnerability to predation related to season and sex in an African ungulate assemblage. Oikos 117:602-610.

Parekh N., Chappell RJ., Millen AE., Albert DM., Mares JA. 2007. Association Between Vitamin D and Age-Related Macular Degeneration in the Third National Health and Nutrition Examination Survey, 1988 Through 1994. Archives of Ophthalmology 125:661669.

Pavey CI., Burwell CJ., Grunwald J-E., Marshall CJ., Neuweiler G. 2001. Dietary Benefits of Twilight Foraging by the Insectivorous Bat. Biotropica 33:670-681.

Periquet S., Todd-Jones L., Valeix M., Stapelkamp B., Elliot N., Wijers M., Pays O., Fortin D., Madzikanda H., Fritz H., Macdonald DW., Loveridge A. J. 2012. Influence of immediate predation risk by lions on the vigilance of prey of different body size. Behavioral Ecology 23:970-976. DOI: 10.1093/beheco/ars060.

Pettigrew JD. 1986. The evolution of binocular vision. In: Pettigrew JD, Sanderson KJ, Levick WR eds. Visual Neuroscience.

Pierscionek BK., Augusteyn RC. 1993. Species Variability In Optical Parameters Of the eye lens. Clinical and Experimental Optometry 76:22-25.

Price AC., Weadick CJ., Shim J., Rodd FH. 2008. Pigments, Patterns, and Fish Behavior. Zebrafish 5:297-307. DOI: 10.1089/zeb.2008.0551.

Richter L., Flodman P., Von-Bischhoffshausen FB., Burch D., Brown S., Nguyen L., Turner J., Spence MA., Bateman JB. 2008. Clinical variability of autosomal dominant cataract, microcornea and corneal opacity and novel mutation in the alpha A crystallin gene (CRYAA). American Journal of Medical Genetics, Part A 146:833-842. DOI: 10.1002/ajmg.a.32236.

Sabbah S., Laria RL., Gray SM., Hawryshyn CW. 2010. Functional diversity in the color vision of cichlid fishes. BMC Biology 8:133.

Schott RK., Refvik SP., Hauser FE., López-Fernández H., Chang BSW. 2014. Divergent positive selection in rhodopsin from lake and riverine cichlid fishes. Molecular Biology and Evolution 31:1149-65. DOI: 10.1093/molbev/msu064.

Shen Y., Lim BK., Liu H., Liu J., Irwin DM., Zhang Y. 2012. Multiple Episodes of Convergence in Genes of the Dim Light Vision Pathway in Bats. PloS One 7:e34564. DOI: 10.1371/journal.pone.0034564.

Siegert S., Cabuy E., Scherf BG., Kohler H., Panda S., Le Y., Fehling HJ., Gaidatzis D., Stadler MB., Roska B. 2012. Transcriptional code and disease map for adult retinal cell types. Nature Neuroscience 15:487-495. DOI: 10.1038/nn.3032. 
833 Sivak JG., Andison ME., Pardue MT. 1999. Vertebrate optical structure. In: Archer S, Djamgoz 834 MB, Loew E, Partridge JC, Vallerg S eds. Adaptive Mechanisms in the Ecology of Vision. 835 London: Chapman and Hall, 73-94.

836 837

Stern DL. 2013. The genetic causes of convergent evolution. Nature Reviews Genetics 14:751764. DOI: $10.1038 / \mathrm{nrg} 3483$.

Stoddard MC., Prum RO. 2011. How colorful are birds? Evolution of the avian plumage color gamut. Behavioral Ecology 22:1042-1052. DOI: 10.1093/beheco/arr088.

Strauss MKL., Packer C. 2013. Using claw marks to study lion predation on giraffes of the Serengeti. Journal of Zoology 289:134-142. DOI: 10.1111/j.1469-7998.2012.00972.x.

Tisdale V., Ferna'ndez-Juricic E. 2009. Vigilance and predator detection vary between avian species with different visual acuity and coverage. Behavioral Ecology 20:936-945. DOI: 10.1093/beheco/arp080.

Trezona PW. 1970. Rod Participation in the "Blue" Mechanism and its effect on Colour Matching. Vision Research 10:317-332.

VanderWaal KL., Wang H., McCowan B., Fushing H., Isbell L a. 2013. Multilevel social organization and space use in reticulated giraffe (Giraffa camelopardalis). DOI: 10.1093/beheco/art061.

Veilleux CC., Kirk EC. 2014. Visual Acuity in Mammals : Effects of Eye Size and Ecology. Brain, Behavior and Evolution 83:43-53. DOI: 10.1159/000357830.

Veilleux CC., Jacobs RL., Cummings ME., Louis EE., Bolnick DA. 2013. Opsin Genes and Visual Ecology in a Nocturnal Folivorous Lemur. International Journal of Primatology. DOI: $10.1007 / \mathrm{s} 10764-013-9708-6$.

Verrelli BC., Lewis CM., Stone AC., Perry GH. 2008. Different selective pressures shape the molecular evolution of color vision in chimpanzee and human populations. Molecular Biology and Evolution 25:2735-2743. DOI: 10.1093/molbev/msn220.

Verrelli BC., Tishkoff SA. 2004. Signatures of selection and gene conversion associated with human color vision variation. American Journal of Human Genetics 75:363-375. DOI: $10.1086 / 423287$.

Villanueva-Canas L., Laurie S., Alba MM. 2013. Improving Genome-Wide Scans of Positive Selection by Using Protein Isoforms of Similar Length. Genome Biology and Evolution 5:457-467. DOI: 10.1093/gbe/evt017.

Warrant EJ., Johnsen S. 2013. Vision and the light environment. Current Biology 23:R990R994. DOI: $10.1016 /$ j.cub.2013.10.019. 
866 Weadick CJ., Chang BSW. 2012. An Improved Likelihood Ratio Test for Detecting Site-Specific 867 Functional Divergence among Clades of Protein-Coding Genes. Molecular Biology and $868 \quad$ Evolution 29:1297-1300. DOI: 10.1093/molbev/msr311.

869 Williams EM. 2016. Giraffe Stature and Neck Elongation: Vigilance as an Evolutionary 870

Winderickx J., Lindsey DT., Sanocki E., Teller DY., Motulsky AG., Deeb SS. 1992. Mechanism. Biology 5:35. DOI: 10.3390/biology5030035. Polymorphism in red photopigment underlies variation in colour matching. Nature 356:431-433.

Winkler M., Shoa G., Tran ST., Xie Y., Thomasy S., Raghunathan VK., Murphy C., Brown DJ., Jester J V. 2015. A Comparative Study of Vertebrate Corneal Structure: The Evolution of a Refractive Lens. Investigative Ophthalmology \& Visual Science 56:2764-2772. DOI: 10.1167/iovs. 15-16584.

Wald BYG. 1935. Carotenoids and the Visual Cycle. The Journal of General Physiology 19:351-371.

Wang Z., Asenjo AB., Oprian DD. 1993. Identification of the $\mathrm{Cl}^{--}$binding site in the human red and green colour vision pigments. Biochemistry 32:2125 - 2130.

Wang D., Oakley T., Mower J., Shimmin LC., Yim S., Honeycutt RL., Tsao H., Li WH. 2004. Molecular Evolution of Bat Color Vision Genes. Molecular Biology and Evolution 21:295302. DOI: $10.1093 / \mathrm{molbev} / \mathrm{msh} 015$.

Wozniak B., Dera J. 2007. Light Absorption in the Sea. New York: Springer.

Yang Z. 2013. User Guide PAML : Phylogenetic Analysis by Maximum Likelihood. 7.

Yang Z., Wong WSW., Nielsen R. 2005. Bayes empirical bayes inference of amino acid sites under positive selection. Molecular Biology and Evolution 22:1107-18. DOI: 10.1093/molbev/msi097.

Ying S., Shiraishi A., Kao CW-C., Converse RL., Funderburgh JL., Swiergiel J., Conrad GW., Kao WW-Y. 1997. Characterization and Expression of the Mouse Lumican Gene. The Journal of Biological Chemistry 272:30306-30313.

Yokoyama S. 2002. Molecular evolution of color vision in vertebrates. Gene 300:69-78.

Yokoyama S., Radlwimmer FB. 1998. The "five-sites" rule and the evolution of red and green color vision in mammals. Molecular Biology and Evolution 15:560-567.

Yokoyama S., Radlwimmer FB. 1999. The Molecular Genetics of Red and Green Color Vision in Mammals. Genetics 153:919-932. 
898 Young TP., Isbell LA. 1991. Sex Differences in Giraffe Feeding Ecology : Energetic and Social $899 \quad$ Constraints. Ethology 87:79-89.

900 Zhang J., Nielsen R., Yang Z. 2005. Evaluation of an improved branch-site likelihood method 901 for detecting positive selection at the molecular level. Molecular Biology and Evolution 902 22:2472-9. DOI: $10.1093 / \mathrm{molbev} / \mathrm{msi} 237$.

903 Zhang J., Kumar S. 1996. Detection of convergent and Parallel Evolution at the Amino Acid $904 \quad$ Sequence Level. Molecular Biology and Evolution14:527-536.

905 Zhao H., Rossiter SJ., Teeling EC., Li C., Cotton JA., Zhang S. 2009. The evolution of color 906 vision in nocturnal mammals. Proceedings of National Academy of Science USA 106:89809078985.

908

909 